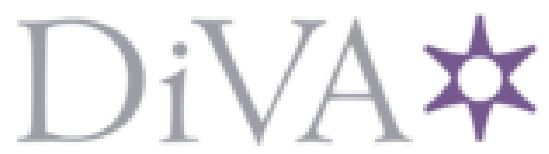

http://www.diva-portal.org

This is the published version of a paper presented at XII International IAEG Congress, Torino, 2014.

Citation for the original published paper:

Döse, M. (2014)

Risk Assessment of Swedish Concrete as a Construction Material in Relation to Naturally Occurring Radiation from Different Aggregates.

In: Giorgio Lollino,Andrea Manconi,Fausto Guzzetti,Martin Culshaw,Peter Bobrowsky,Fabio Luino (ed.), Springer

N.B. When citing this work, cite the original published paper.

Permanent link to this version:

http://urn.kb.se/resolve?urn=urn:nbn:se:kth:diva-192953 

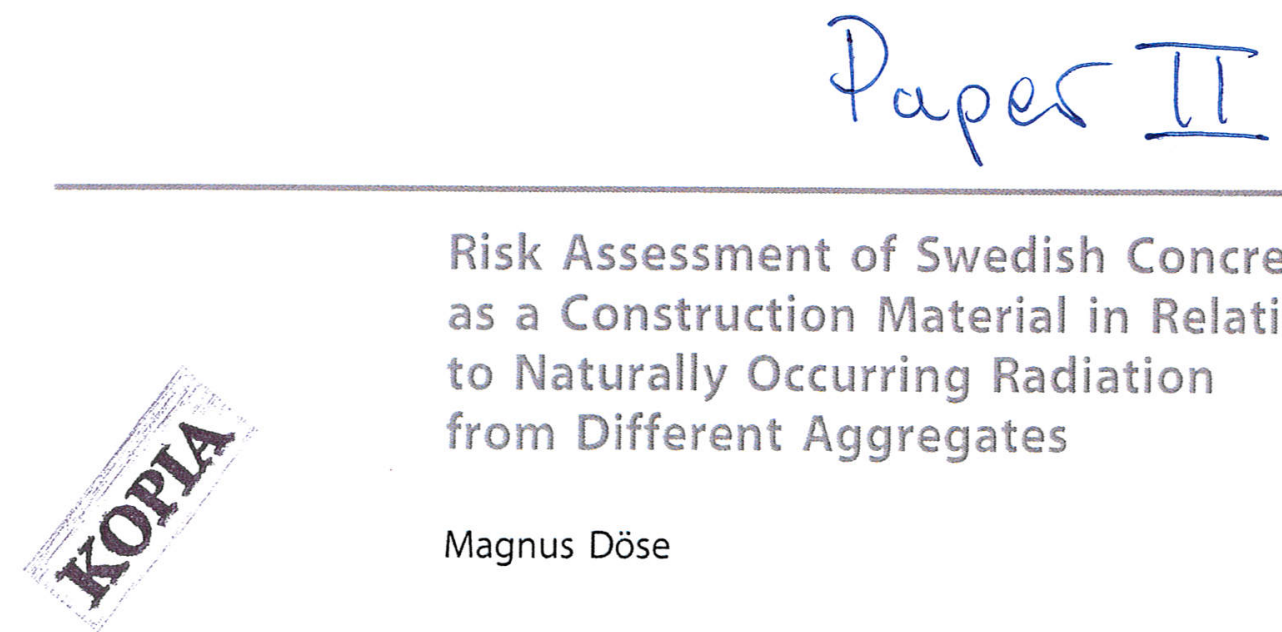

\title{
Risk Assessment of Swedish Concrete as a Construction Material in Relation to Naturally Occurring Radiation from Different Aggregates
}

\author{
Magnus Döse
}

\begin{abstract}
The European Commission (EC) has, since 1996, prescribed regulations concerning ionizing radiation from building materials. The current threshold value suggested for free circulation of building materials without restrictions are $1 \mathrm{mSv} /$ year (EC 2013). By use of full scale concrete slabs of dimensions $1.5 \mathrm{~m} \times 1.5 \mathrm{~m} \times 0.15 \mathrm{~m}$, an empirical approach is suggested for the calculation of Activity Index (I-index) of naturally occurring ionizing radioactivity from building materials. The concrete slabs simulate a pre-cast concrete wall. Measurements of ${ }^{40} \mathrm{~K}$, ${ }^{226} \mathrm{Ra}$ and ${ }^{232} \mathrm{Th}$ are performed in order to assess the I-index, equivalent dose (AEDE), equivalent dose rate (AEDR) and some common international indices. The results indicate that $\sim 70 \%$ of the investigated building materials are in agreement with the stipulated levels set out by UNSCEAR (2000) for outdoor conditions. In relation to the I-index, 6 out of the 10 concrete slabs satisfactorily met the safety criterion (Activity Index $<1$ ). Some aggregates fail to comply with the stipulated threshold value (EC 2013). The cause is not only a significant uranium source $\left({ }^{226} \mathrm{Ra}\right.$ ), but more frequently an increased level of ${ }^{232} \mathrm{Th}$ in some of the investigated concrete mixes. By and large, most indices are comparable and give a similar indication of a construction/building materials risk to produce naturally ionizing radiation to habitants. The study further suggests that an empirical approach by use of a field gamma spectrometer results in a good linear correlation with results achieved from laboratory gamma ray spectrometry analysis and consequently the empirical approach could as such be used to approximately calculate the I-index.
\end{abstract}

Keywords

Building materials $\cdot$ Ionizing radiation - Activity index $\cdot$ Gamma radiation Concrete

\subsection{Introduction}

The naturally occurring radioactive nuclides, used for evaluation of radiological risk assessment are ${ }^{232} \mathrm{Th},{ }^{226} \mathrm{Ra}$ and ${ }^{40} \mathrm{~K}$ as well as the total gamma radiation within the energy field $40-2,840 \mathrm{keV}$. It is of importance for authorities, regulators as well as for habitants to evaluate the effects of these

M. Döse $(\triangle)$

Swedish Cement and Concrete Research Institute, c/o SP, Box 857,50115 , Borås, Sweden

e-mail: magnus.dose@cbi.se radioactive nuclides impact on human health and to assess the risks for use of the products aimed for dwellings (IAEA 2011; EC 2013).

Concrete used for dwellings contains several different components, including aggregates, cement, water, adhesives, filler (often limestone) and sometimes slag or fly ash. All building materials/construction products contain various amounts of naturally occurring materials emitting ionizing radiation, and within the Swedish concrete industries the aggregates are the largest contributor (Möre 1985; Mjönes 1986). The industrial usage of aggregates for concrete, within Sweden constitutes approximately $80 \%$ crushed rock 
(crushed granite/gneiss) and $20 \%$ natural gravel/fluvial sediments (Göransson 2011).

In some cases, concrete can contain waste residues, more clearly addressed by the EC as NORMs. NORMs are listed and clearly defined in a recommendation presented by the European Commission report 122 (2001). Hence, it should be addressed that, within this article, an approach to solely evaluate the naturally occurring ionizing radiation from crushed bedrock, such as granites and gneisses are primarily discussed and evaluated. By use of a field mass spectrometer, RS 230 , a simple method is used to correctly calculate the I-index as suggested by the EC $(1996,1999)$ and to compare the results with existing indices distributed by different authorities/authors (UNSCEAR 2000; Krisiuk et al. 1971; Beretka and Mathew 1985). The equivalent dose (AEDE) could be assessed as equal to effective dose assuming full body irradiation (IAEA 2003).

The tested aggregates/materials are collected from 10 different quarries within the Gothenburg and Stockholm region encompassing the area between the two major cities of Sweden.

Current regulations in Sweden are only related to the total gamma-radiation, which has an acceptance level of $0.3 \mu \mathrm{Sv} /$ h (The Swedish National Board of Housing, Building and Planning 2012). There are currently no regulations in the Swedish legislations in relation to the I-index. Nevertheless, in the light of the legislation of the European Commission Council directive 89/106/EEC, the EU's Basic Safety Standards (2013) and the Construction Products Regulation (CPR) for EC-declaration of performance of building materials, the assumption is that the Swedish industry will be forced to adapt to the criteria set out by the European Commission (EC).
The risk assessment indices are summarized in Table 20.1, where the total dose rate, the Activity Index (I) as well as the Annual Effective Dose Equivalent (AEDE) and the Annual Effective Dose Rate (AEDR) is presented. The $\mathrm{H}_{\mathrm{ex}}, \mathrm{H}_{\mathrm{in}}$ and $\mathrm{Ra}_{\mathrm{Eq}}$ calculations are presented in italics, and are not further discussed within this paper. This is due to the different set out criteria/threshold values, on which they are based. The basis for the indices, $\mathrm{H}_{\mathrm{ex}}, \mathrm{H}_{\mathrm{in}}$ and $\mathrm{Ra}_{\mathrm{Eq}}$ are $1.5 \mathrm{mGy} / \mathrm{year}$. The I-index is based on calculations of $1 \mathrm{mSv} / \mathrm{a}$ (EC 1999).

\subsection{Methods}

\subsubsection{Basic Concept of Measurements}

The concept and basic method of this study relies on measurements attained using a field spectrometer (hand held spectrometer), supplied by Radiations Solutions Inc. The spectrometer model, RS 230, uses a Bismuth Germanium Oxide-crystal, in order to enhance the sensitivity. The total count (gamma radiation in $\mu \mathrm{Sv} / \mathrm{h}$ ), as well as the spectra of ${ }^{226} \mathrm{Ra},{ }^{232} \mathrm{Th}$ and ${ }^{40} \mathrm{~K}$ have been recorded. Ten separate measurements of $4 \mathrm{~min}$ each have been sampled on every investigated concrete slab. Measurements have been registered from the centre, twice by rotating the spectrometer perpendicular to the first reading, 20 and $40 \mathrm{~cm}$ from the centre of the cast concrete in four different directions, yielding a total of ten separate measurements on each concrete slab.

Concrete as a material is not a perfectly homogenous material. In order to avoid any anomaly, due to, for example, one measurement, such as heterogeneously distributed aggregate, the separate measurements have been added

Table 20.1 The table shows the mean calculation of the dose rate $(\mu \mathrm{Sv} / \mathrm{h})$ as well as the mean total mass activity of ${ }^{40} \mathrm{~K}$, ${ }^{226} \mathrm{Ra}$ and ${ }^{232} \mathrm{Th}$ for each concrete slab (sample)

\begin{tabular}{|c|c|c|c|c|c|c|c|c|c|c|c|c|}
\hline \multirow[t]{2}{*}{$\begin{array}{l}\text { Concrete } \\
\text { samples }\end{array}$} & \multirow[t]{2}{*}{$\begin{array}{l}\text { Dose rate } \\
(\mu \mathrm{S} v / \mathrm{h})\end{array}$} & \multicolumn{3}{|c|}{$\begin{array}{l}\text { Specific activity }(\mathrm{Bq} / \mathrm{kg}) \\
\text { measured by } \mathrm{CBI}\end{array}$} & \multirow{2}{*}{$\begin{array}{l}\text { Activity- } \\
\text { value, I } \\
\text { (CBI) }\end{array}$} & \multirow{2}{*}{$\begin{array}{l}\text { Activity- } \\
\text { value, I } \\
\text { (STUK) }\end{array}$} & \multirow[t]{2}{*}{$\begin{array}{l}\text { AEDR } \\
\text { (STUK) }\end{array}$} & \multirow[t]{2}{*}{ AEDE } & \multirow[t]{2}{*}{ AEDR } & \multirow[t]{2}{*}{$R a_{E q}$} & \multirow[t]{2}{*}{$H_{e x}$} & \multirow[t]{2}{*}{$H_{i n}$} \\
\hline & & ${ }^{40} \mathrm{~K}$ & ${ }^{226} \mathrm{Ra}$ & ${ }^{232} \mathrm{Th}$ & & & & & & & & \\
\hline 1 & 0.25 & 1134.6 & 157.8 & 134.9 & 1.58 & 2.04 & 1.35 & 1.07 & 1.04 & 438.10 & 1.18 & 1.61 \\
\hline 2 & 0.25 & 1216.2 & 92.3 & 168.5 & 1.56 & 1.79 & 1.17 & 1.05 & 1.02 & 426.87 & 1.15 & 1.40 \\
\hline 3 & 0.20 & 1283.3 & 118.7 & 87.7 & 1.26 & 1.49 & 0.97 & 0.84 & 0.83 & 342.94 & 0.93 & 1.25 \\
\hline 4 & 0.14 & 748.1 & 53.7 & 92.6 & 0.89 & 1.02 & 0.67 & 0.60 & 0.58 & 243.39 & 0.66 & 0.80 \\
\hline 5 & 0.10 & 983.3 & 26.1 & 47.2 & 0.65 & 0.65 & 0.42 & 0.43 & 0.42 & 169.40 & 0.46 & 0.53 \\
\hline 6 & 0.10 & 871.2 & 42.7 & 42.5 & 0.65 & 0.60 & 0.39 & 0.43 & 0.42 & 170.60 & 0.46 & 0.58 \\
\hline 7 & 0.09 & 852.3 & 45.3 & 39.2 & 0.63 & 0.59 & 0.38 & 0.43 & 0.41 & 166.84 & 0.45 & 0.57 \\
\hline 8 & 0.08 & 704.3 & 42.5 & 31.6 & 0.53 & 0.50 & 0.33 & 0.43 & 0.35 & 141.83 & 0.38 & 0.50 \\
\hline 9 & 0.08 & 606.1 & 39.6 & 31.1 & 0.49 & 0.44 & 0.29 & 0.33 & 0.32 & 130.73 & 0.35 & 0.46 \\
\hline 10 & 0.04 & 381.9 & 22.0 & 15.3 & 0.28 & 0.15 & 0.10 & 0.18 & 0.34 & 73.28 & 0.2 & 0.26 \\
\hline
\end{tabular}

The effective dose according to UNSCEAR and I-index have been calculated. The I-index have also been calculated for results from the mass activity of ${ }^{40} \mathrm{~K},{ }^{226} \mathrm{Ra}$ and ${ }^{232} \mathrm{Th}$ for results acquired from STUK. In italics, corresponding values of $\mathrm{H}_{\mathrm{ex}}, \mathrm{H}_{\text {in }}$ and $\mathrm{Ra}_{\mathrm{Eq}}$ are shown. Bold digits suggest that threshold values have been reached 
together and a mean value of gamma radiation as well as the three radioactive nuclides are presented in Table 20.1. The relative humidity $(\mathrm{RH})$ has been measured to be in the interval 90-95\%, measuring each concrete slab $\sim 1$ month after casting. The resolution (FWHM) have been predominantly between 4 and $5 \%$ measuring the peak area of ${ }^{232} \mathrm{Th}$.

The recipe used for the concrete followed the suggested sieve curve presented in EN 1766 (2000). The water/cement (w/c) ratio has, for all ten concrete slabs, been between 0.45 and 0.5. A CEM II-Portland cement (Skövde byggcement), has been used for every concrete cast. The different crushed aggregates contain five granites, two granitic gneisses, two metasedimentary gneiss, and one metagabbro.

\subsubsection{Control and Validation of Results}

Correlation and subsequent control of the cast quality as well as the ionizing radiation measured from the concrete slabs were achieved by sawing the cast concrete slab, from the centre of the slab, in four squares $(0.3 \mathrm{~m} \times 0.3 \mathrm{~m})$, each square as such, thus represents, at least three readings, out of ten, from the measurements on the full scale cast slab. One of the squares, from each concrete slab were crushed, dried and sent for external analysis of gamma spectrometry. The crushed concrete were reduced in accordance with SS-EN 932-2 (Swedish Standard Institute 1999) and approximately 3-4 kg, were sent for analysis. The laboratory analytical procedure for gamma ray analysis (in house guide VALO 4.5) were conducted by the Radiation and Nuclear Safety Authority of Finland (STUK).

\subsection{Results}

The range of values (Table 20.1) for dose rate in air (uSv/h) measured on the concrete slabs varies from a maximum of $0.25-0.08 \mu \mathrm{Sv} / \mathrm{h}$ with a median value of $0.10 \mu \mathrm{Sv} / \mathrm{h}$ and a mean value of $\sim 0.14 \mu \mathrm{Sv} / \mathrm{h}$. For the I-index the maximum value is $1.6(2.04)^{1}$ with a minimum of $0.28(0.15)^{1}$, with a median value of 0.65 .

The results imply, that 6 out of 10 investigated concrete slabs have satisfactorily met the safe criterion $(I<1)$, stipulated by the EU-Commission (Radiation Protection 112 (1996). The three samples yielding the highest values show results in the interval, $\mathrm{I}=1.3-1.6(1.5-2.0)^{1}$. Correlating with results from STUK (yet one more sample reaches the critical acceptance criterion $(>1)$, let alone being a border liner). Results of the mass activity from STUK show a

1 Results based on calculation of the nuclides ${ }^{232} \mathrm{Th},{ }^{226} \mathrm{Ra}$ and ${ }^{40} \mathrm{~K}$ from the same concrete material as measured by CBI. Analysis performed by Nuclear Safety Authority of Finland (STUK).

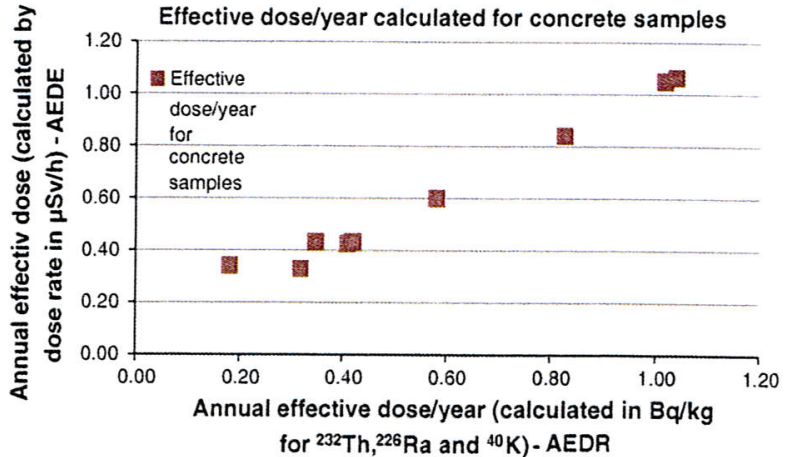

Fig. 20.1 Displays compared values calculated using the total gamma radiation $(A E D E)$ versus the three nuclides $\left({ }^{232} \mathrm{Th},{ }^{226} \mathrm{Ra}\right.$ and $\left.{ }^{40} \mathrm{~K}\right)$ investigated (AEDR). The linearity implies no disturbing background elements, unless at the lower intervals

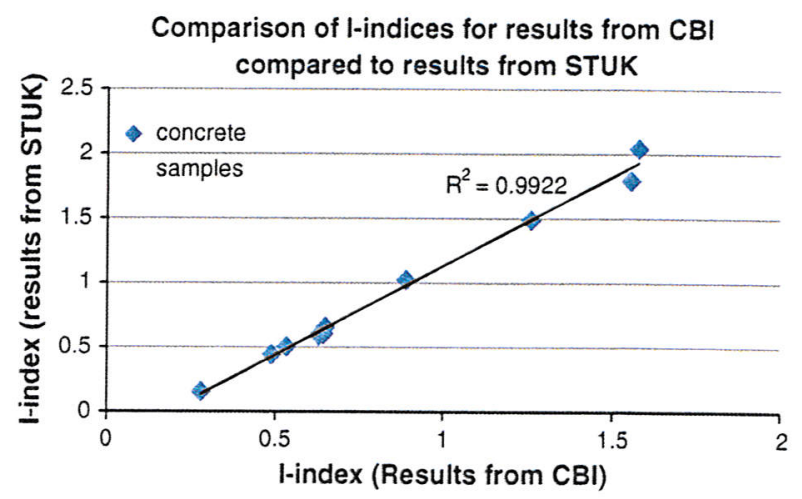

Fig. 20.2 Displays a linear correlation between measurements performed on concrete slabs by $\mathrm{CBI}$, compared to the results from the same concrete slabs, which had been cut, crushed and sent for gamma spectrometry analysis at STUK. $\mathrm{R}^{2}=0.99$

fairly good correlation in the medium to lower intervals (I-index $<1$ ). For I-index $>1$ there are consistent readings of $10-25 \%$ higher compared to results presented from the concrete slabs measured by $\mathrm{CBI}$.

When correlating the AEDE and AEDR results, a linear correlation is desirable (see Fig. 20.1). Correlating the mass activity measurements performed by CBI with the results from STUK a strong linear correlation could be established $\left(\mathrm{R}^{2}=0.99 \%\right.$, Fig. 20.2).

\subsection{Discussion}

None of the investigated building materials exceeded the Swedish threshold value $0.3 \mu \mathrm{Sv} / \mathrm{h}$ (The Swedish National Board of Housing, Building and Planning (2012). However, the geometrical arrangement of a room has not been taken 
into account, when measurements have been performed by CBI, using a $2 \pi$ configuration set up, and as such the I-index is more correct and easier to apply, since this geometrical arrangement is already considered in the model. An increase of $\sim 45-50 \%$ in effective dose compared to outdoors conditions are to be expected (Markkanen 1995) when considering a room model.

In general, two out of ten samples show results exceeding the recommendations set out by the UNSCEAR (2000). The I-index has a lower acceptance level. This is valid, since it is considered to be a conservative model (Markkanen 1995; EC 1999). The I-index is derived through a mathematical model (the Berger model) using "attenuation and build up" (Markkanen 1995) assuming a block model room, with a $20 \mathrm{~cm}$ thick concrete enclosure, without windows and doors. This means that a worst case scenario is calculated. Furthermore, the thickness (default $20 \mathrm{~cm}$ ), as well as the density $\left(2,350 \mathrm{~kg} / \mathrm{m}^{3}\right)$ are fixed values, meaning there are no adjustable variables in the model. However, an approach to give the model more flexibility is made by Maringer et al. (2013), where the density, as well as the thickness of the walls, are considered as variables in the I-index.

For materials exceeding the stipulated levels of $1 \mathrm{mSv} /$ year, an approach of a separate dose assessment is under review by the European Commission, taking into consideration the full extent of its use within the dwelling. A technical report describing assessment of effective dose for building materials is likely to be presented during 2014 .

The comparison of the background influence (see Fig. 20.1-AEDE) in relation to AEDR implies a vague background influence at lower levels. The strong correlation of $\mathrm{R}^{2}$ (see Fig. 20.2) suggests that the simplified methodology, such as the one described, using a hand held spectrometer, can be used to calculate the I-index fairly correctly, by use of a correlation coefficient.

\subsection{Conclusion}

The recommended levels from building materials in annual effective dose is set to a maximum of $1 \mathrm{mSv} /$ year EC (1996, 1999), ICRP (2007), EC (2013). Some investigated concrete cast mixes with different swedish aggregates, do not met the safety criterion stipulated by the European Commission (2013), ICRP (2007, 2008), IAEA (2011). This is commonly due to partly an increased level of ${ }^{226} \mathrm{Ra}$, but also an increased level of ${ }^{232} \mathrm{Th}$ in some of the most strongly radiating construction materials.
The I-index displays a stricter threshold value, where three out of ten samples are clearly above the stipulated levels defined by the EC. The annual effective dose equivalent (AEDE) as well as annual effective dose rate (AEDR) give values only marginally above the suggested criterion for outdoor exposure (UNSCEAR 2000).

By and large, most indices are comparable and give a similar indication of a construction/building materials risk to produce naturally ionizing radiation to habitants.

The empirical approach measuring with use of a field spectrometer give a firm linear correlation with results achieved from STUK, using laboratory gamma ray spectrometry analysis. Consequently a simplified arrangement using large concrete castings, with a minimum area of $1.5 \mathrm{~m} \times 1.5 \mathrm{~m}$ can be proposed to roughly calculate the I-index.

Acknowledgments Special thanks to the Swedish Consortium for Basic Research, who has partly funded and supported the research and the project using empirical data. Also, I greatly appreciate support by Seppo Klemola/STUK, who has commented to the results and their interpretation thereof. Finally, many thanks to my colleagues at $\mathrm{CBI}$ Borảs, who has contributed with strong efforts to produce all the concrete casts necessary during this project.

\section{References}

Beretka I, Matthew PI (1985) Natural radioactivity of Australian building materials. Waste and byproducts. Health Phys 48:87-95

EC (European Commission) (1996) Radiation protection 96- enhanced radioactivity of building materials

EC (European Commission) (1999) Directorate-general environment, nuclear safety and civil protection. Radiological protection principles concerning the natural radioactivity of building material. Radiation protection 112

EC (Council of the European Union) (2013) Council Directive laying down basic safety standards for protection against the dangers arising from exposure to ionizing radiation

EC (European Commission) (2001) Radiation protection 122Practical use of the concepts of clearance and exemption-Part II. Application of the concepts of exemption and clearance to natural radiation sources

EN 1766 (2000) Products and systems for the protection and repair of concrete structures-Test methods-Reference concretes for testing

Göransson M (2011) Ersättningsmaterial för naturgrus-kunskapssammanställning och rekommendationer för användningen av naturgrus. SGU-report, 2011-10

IAEA (2003) TECDOC-1363: guidelines for radioelement mapping using gamma ray spectrometry data

IAEA Safety Standards (2011) Radiation and safety of radiation sources: international basic safety standards-Interim edition

ICRP (2007) Recommendations of the international commission on radiological protection, ICRP Publication 103, Ann. ICRP 37 
Krisiuk EM, Tarasov SI, Shamov VP, Shalak NI, Lisachenko EP, Gomelsky LG (1971) A study on radioactivity in building materials. Research Institute for Radiation Hygiene, Leningrad

Maringer FJ, Baumgartner A, Rechberger F, Seidel C, Stietka M (2013) Activity measurement and effective dose modeling of natural radionuclides in building material. Appl Radiat Isot 81:279--283

Mjönes L (1986) Gamma radiation in Swedish dwellings. Radiat Prot Dosim 15:2

Möre H (1985) Radioaktiva ämnen i byggnadsmaterial. SSI-report. 85-08
Markkanen M (1995) Radiation dose assessments for material with elevated natural radioactivity. STUK-B-STO 32

New ICRP Recommendations (2008) J Radiol Prot 28

Swedish Standard Institute (1999) SS-EN 932-2: Test for general properties of aggregates, part 2: methods for reducing laboratory samples

The Swedish National Board of Housing, Building and Planning (2012) BBR 6:12

UNSCEAR (2000) United nations scientific committee of the effects of atomic radiation. Report to the General Assembly, New York 